\title{
Increased serum resistin level is associated with coronary heart disease
}

\author{
Jing-Zhan Zhang ${ }^{1,2}$, Ying Gao ${ }^{3}$, Ying-Ying Zheng ${ }^{1}$, Fen Liu ${ }^{1}$, Yi-Ning Yang ${ }^{1}$, Xiao- \\ Mei $\mathrm{Li}^{1}$, Xiang $\mathrm{Ma}^{1}$, Yi-Tong $\mathrm{Ma}^{1}$ and Xiang $\mathrm{Xie}^{1}$ \\ ${ }^{1}$ Department of Cardiology, First Affiliated Hospital of Xinjiang Medical University, Urumqi, China \\ 2 Department of Dermatology, People's Hospital of Xinjiang Uygur Autonomous Region, Urumqi, China \\ ${ }^{3}$ Department of Cadre Ward, First Affiliated Hospital of Xinjiang Medical University, Urumqi, China \\ Correspondence to: Xiang Xie, email: xiangxie999@sina.com
}

Keywords: coronary heart disease; serum resistin; meta-analysis

Received: November 24, $2016 \quad$ Accepted: January 24, 2017

Published: February 25, 2017

Copyright: Zhang et al. This is an open-access article distributed under the terms of the Creative Commons Attribution License 3.0 (CC BY 3.0), which permits unrestricted use, distribution, and reproduction in any medium, provided the original author and source are credited.

\section{ABSTRACT}

To explore the relationship between the serum resistin level and different types of coronary heart diseases (CHD). Literature was retrieved by formal searching of PubMed, Web of Science, Google Scholar, the Cochrane Library, Wanfang Data, China Biological Medicine Database (SinoMed) and China National Knowledge Infrastructure (CNKI) and by hand searching of reference lists of related articles. RevMan5.3 statistical software was utilized for processing and analysis. A total of 22 literatures involving 2070 subjects were included. Meta-analysis showed that the level of serum resistin in the patients with stable angina (SA), unstable angina(UA) or acute myocardial infarction (AMI) were significantly higher than those of normal controls, respectively $[\mathrm{SMD}(95 \% \mathrm{CI})$ were $1.97(1.15,2.79), 2.54(1.76,3.31)$, and $3.62(2.62$, 4.62), all $P<0.00001]$. Serum resistin level in patients with UA or AMI was higher than those in patients with $S A$, respectively $[S M D=0.90,95 \mathrm{CI}(0.28,1.52), P=0.005]$, $[S M D=2.28,95 \% \mathrm{CI}(0.74,3.82), P=0.004]$. The level of serum resistin in patients with AMI was also higher than those in patients with UA $[S M D=1.22,95 \% \mathrm{CI}(0.58,1.85)$, $P=0.0002]$. The study demonstrated that increased serum resistin level is significantly associated with the severity of CHD.

\section{INTRODUCTION}

Coronary heart disease (CHD) is the occurrence of coronary atherosclerosis events that causes the stenosis or obstruction of the vessel lumen and leading to cardiac ischemia, anoxia or necrosis. Chronic inflammation is considered to be a risk factor for increasing the risk of coronary events, which can make atherosclerotic plaques in coronary artery prone to rupture $[1,2]$. Resistin is a newly discovered adipocyte factor. Since the discovery of resistin, many studies mainly focused on the relationship among it with insulin resistance and obesity, and suggested that resistin may be an important factor which can lead to obesity, insulin resistance and type 2 diabetes mellitus (T2DM).

In recent years, some studies show that resistin is related to many inflammatory markers and may be involved in the atherosclerosis, which plays an important role in the development of CHD. The relationship between serum resistin level and the severity of CHD has attracted significant clinical research interest. Therefore, we conducted a meta-analysis of the existing published studies on this topic to evaluate the strength of the association between serum resistin level and CHD.

\section{RESULTS}

Study characteristics

We retrieved a total of 192 studies. After duplicates removed, only 129 full-text studies were evaluated. After exclusion of review articles, a total of 22 studies [3-24] were included in the final meta-analysis according to 
Table 1: Characteristics of the studies reporting the serum resistin level and different types of CHD

\begin{tabular}{|c|c|c|c|c|c|c|c|c|c|c|c|c|c|c|c|}
\hline \multirow{2}{*}{ First author } & \multirow{2}{*}{ Publication year } & \multirow{2}{*}{ Country } & \multirow{2}{*}{ Detection Assay } & \multicolumn{3}{|c|}{ Normal control group } & \multicolumn{3}{|c|}{ SA group } & \multicolumn{3}{|c|}{ UA group } & \multicolumn{3}{|c|}{ AMI group } \\
\hline & & & & Mean & $\mathrm{SD}$ & $\mathrm{N}$ & Mean & $\mathrm{SD}$ & $\mathrm{N}$ & Mean & $\mathrm{SD}$ & $\mathrm{N}$ & Mean & $\mathrm{SD}$ & $\mathrm{N}$ \\
\hline $\mathrm{Cao}[3]$ & 2009 & China & ELISA & 3.17 & 0.35 & 40 & & & & 3.7 & 0.59 & 52 & 4.49 & 0.76 & 50 \\
\hline $\mathrm{Chu}[4]$ & 2008 & China & ELISA & 4.17 & 2.24 & 26 & & & & 7.34 & 3.44 & 19 & 15.12 & 5.06 & 20 \\
\hline Geng[5] & 2013 & China & ELISA & 0.57 & 0.08 & 30 & & & & 0.96 & 0.11 & 30 & 1 & 0.11 & 30 \\
\hline Guo[6] & 2008 & China & ELISA & 0.22 & 0.15 & 15 & 1.99 & 0.83 & 31 & 3.46 & 0.99 & 23 & 4.76 & 0.85 & 19 \\
\hline Huang[7] & 2006 & China & ELISA & 8.92 & 7.8 & 24 & 16.18 & 7.8 & 24 & 18.78 & 8.56 & 12 & 26.74 & 8.7 & 28 \\
\hline Erer[8] & 2013 & Turkey & ELISA & 2 & 1.05 & 33 & & & & & & & 3.71 & 4.2 & 132 \\
\hline Korah[9] & 2011 & Egypt & ELISA & 5.47 & 0.81 & 15 & & & & & & & 13.59 & 3.6 & 40 \\
\hline $\mathrm{Li}[10]$ & 2006 & China & ELISA & 4.17 & 2.24 & 26 & & & & 7.67 & 4.28 & 18 & 15.12 & 5.06 & 19 \\
\hline $\mathrm{Li}[11]$ & 2011 & China & ELISA & 0.13 & 0.28 & 35 & 0.14 & 0.13 & 35 & 0.18 & 0.23 & 69 & & & \\
\hline Liu[12] & 2004 & China & ELISA & 3.2 & 0.48 & 30 & 5.68 & 1.49 & 22 & 5.79 & 1.52 & 20 & 5.86 & 1.67 & 18 \\
\hline $\operatorname{Liu}[13]$ & 2010 & China & ELISA & 1.09 & 0.35 & 8 & 2.41 & 0.67 & 12 & 4.87 & 1.72 & 28 & & & \\
\hline $\mathrm{Ma}[14]$ & 2008 & China & ELISA & & & & 2.1 & 0.7 & 40 & & & & 4.1 & 0.8 & 37 \\
\hline Qiao[15] & 2007 & China & ELISA & & & & 3.45 & 0.56 & 22 & 5.59 & 0.75 & 19 & 8.16 & 0.79 & 24 \\
\hline Sang[16] & 2009 & China & ELISA & 6.94 & 0.9 & 20 & & & & 10.42 & 0.7 & 18 & 12.49 & 0.88 & 18 \\
\hline $\operatorname{Sinan}[17]$ & 2014 & Turkey & ELISA & 0.017 & 0.0085 & 50 & 0.02539 & 0.0134 & 80 & 0.025 & 0.018 & 39 & & & \\
\hline Tang[18] & 2011 & China & ELISA & 7.4 & 2.1 & 40 & & & & & & & & & \\
\hline Wang[19] & 2009 & China & ELISA & 0.49 & 0.4 & 67 & 0.66 & 0.4 & 70 & & & & & & \\
\hline Wang[20] & 2010 & China & ELISA & 3.17 & 0.15 & 30 & 5.41 & 0.27 & 18 & 5.61 & 0.28 & 20 & 5.65 & 0.33 & 22 \\
\hline Wang[21] & 2012 & China & ELISA & 6.94 & 0.9 & 20 & & & & 10.42 & 0.7 & 25 & & & \\
\hline Wang[22] & 2012 & China & ELISA & 44.68 & 6.89 & 25 & & & & 49.23 & 7.81 & 25 & 54.17 & 8.57 & 25 \\
\hline $\mathrm{Y}$ ang $[23]$ & 2011 & China & ELISA & 0.262 & 0.1119 & 90 & 0.5183 & 0.1284 & 93 & & & & & & \\
\hline Zhang[24] & 2009 & China & ELISA & 12.16 & 2.64 & 24 & & & & 19.16 & 1.18 & 30 & 23.46 & 1.49 & 46 \\
\hline
\end{tabular}

CHD Coronary heart disease, SA stable angina, UA unstable angina, AMI acute myocardial infarction, SD standard deviation, N sample number, ELISA Enzymelinked Immunosorbent Assay

the inclusion criteria. There are 2070 subjects, including 648 control subjects and 1422 CHD patients (447 cases in SA group, 447 cases in UA group, 528 cases in AMI group). The NOS results showed that the methodological quality was generally high. Figure 1 shows the process of literature selection. Table 1 showed the characteristics of included studies.

\section{Main results and heterogeneity}

\section{Association of resistin level with SA}

There are 9 studies reporting the association of resistin level with SA. $\mathrm{I}^{2}$ test indicated that the heterogeneity is significant $\left(P<0.00001, \mathrm{I}^{2}=95.0 \%\right)$, therefore, the random-effects model (DerSimonian and Laird) was applied to perform meta-analysis. We found serum resistin level in SA group is higher than that in normal control group [standard mean difference $(\mathrm{SMD})=$ 1.97, 95\%CI: 1.15-2.79, $P<0.00001]$ (Figure 2).

\section{Association of resistin level with UA}

There are 15 studies reporting the association of resistin level with UA. $\mathrm{I}^{2}$ test indicated that the heterogeneity is significant $\left(P<0.00001, \mathrm{I}^{2}=95.0 \%\right)$, therefore, the random-effects model (DerSimonian and Laird) was applied to perform meta-analysis. Serum resistin level of UA is higher than that in normal control group $[\mathrm{SMD}=2.54,95 \% \mathrm{CI}: 1.76-3.31, P<0.00001]$ (Figure not shown).

\section{Association of resistin level with AMI}

There are 13 studies reporting the association of resistin level with AMI. $\mathrm{I}^{2}$ test indicated that the heterogeneity is significant $\left(P<0.00001, \mathrm{I}^{2}=95.0 \%\right)$, therefore, the random-effects model (DerSimonian and Laird) was applied to perform meta-analysis. The results show that AMI serum resistin level is higher than that in normal control group [SMD $(95 \% \mathrm{CI})=3.62(2.62,4.62)$, $P<0.00001$ ] (Figure not shown).

\section{Comparison of UA with SA in serum resistin level}

There are 8 studies reporting the association of resistin level with UA compared to SA. $\mathrm{I}^{2}$ test indicated that the heterogeneity is significant $(P<0.00001$, $\left.\mathrm{I}^{2}=89.0 \%\right)$, therefore, the random-effects model (DerSimonian and Laird) was applied to perform metaanalysis. The results show that serum resistin level in UA group is higher than that in SA group [SMD $(95 \% \mathrm{CI})=$ $0.90(0.28,1.52), P<0.05]$ (Figure 3 ).

\section{Comparison of AMI with $\mathrm{SA}$ in serum resistin level}

There are 5 studies reporting the association of resistin level with AMI compared to SA. $\mathrm{I}^{2}$ test indicated that the heterogeneity is significant $(P<0.00001$, $\left.\mathrm{I}^{2}=95.0 \%\right)$, therefore, the random-effects model (DerSimonian and Laird) was applied to perform meta- 
analysis. The results show that AMI serum resistin level is higher than SA group [SMD $(95 \% \mathrm{CI})=2.28(0.74,3.82)$, $P=0.005]$.

\section{Comparison of AMI with $\mathrm{UA}$ in serum resistin level}

There are 12 studies reporting the association of resistin level with AMI compared to UA. $I^{2}$ test indicated that the heterogeneity is significant $(P<$ $0.00001, \mathrm{I}^{2}=92.0 \%$ ), therefore, the random-effects model (DerSimonian and Laird) was applied to perform meta- analysis. The results show that AMI serum resistin level is higher than UA group [SMD $(95 \% \mathrm{CI})=1.22(0.58,1.85)$, $P=0.0002]$.

\section{Sensitivity analysis}

The contribution of each study to the pooled estimate was performed in order to assess the sensitivity analyses. We excluded one individual study at a time and recalculated the pooled $P$ or OR. All studies did not substantially change the pooled point estimate, which indicated the reliability of our results.

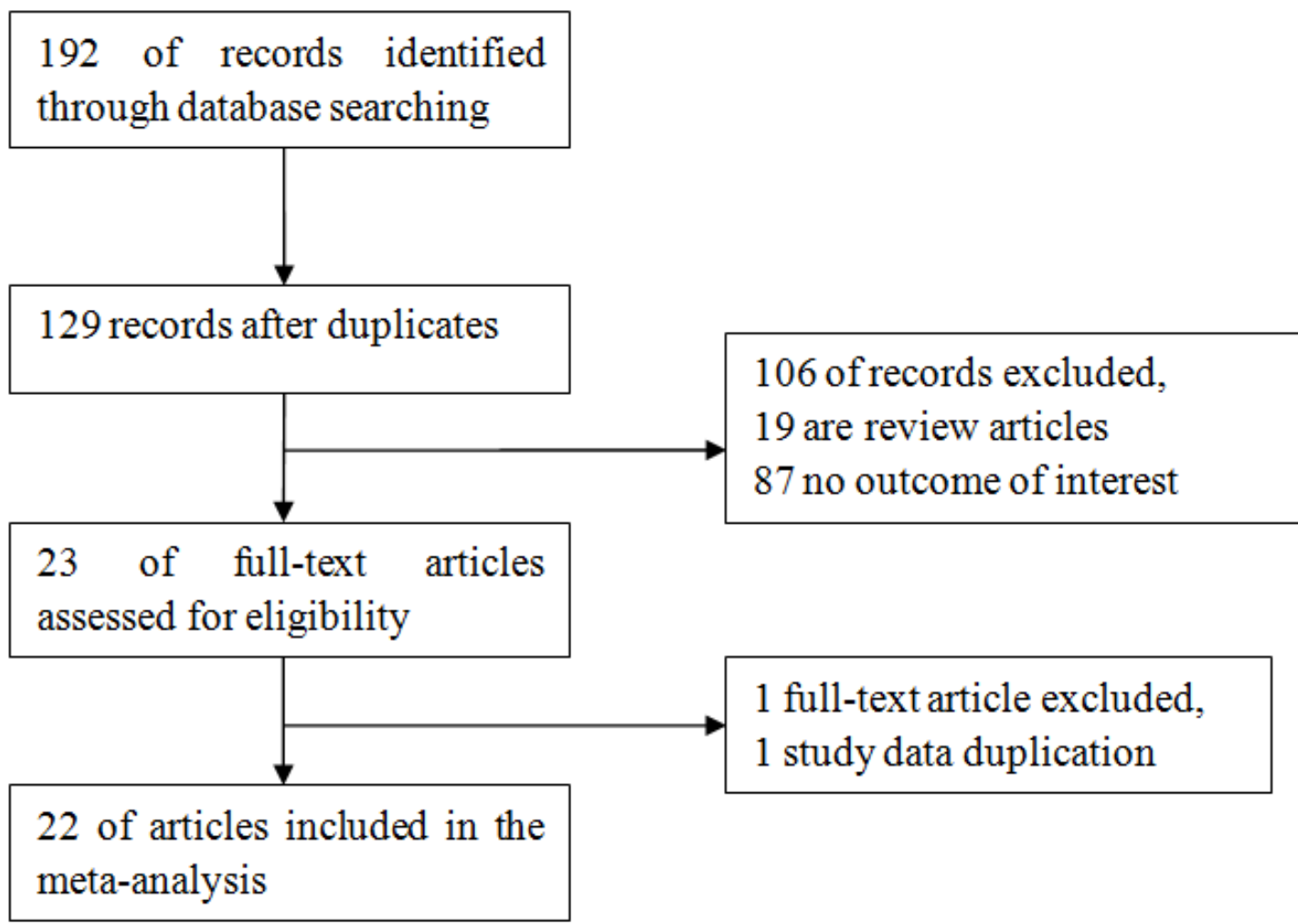

Figure 1: Flow diagram of study identification.

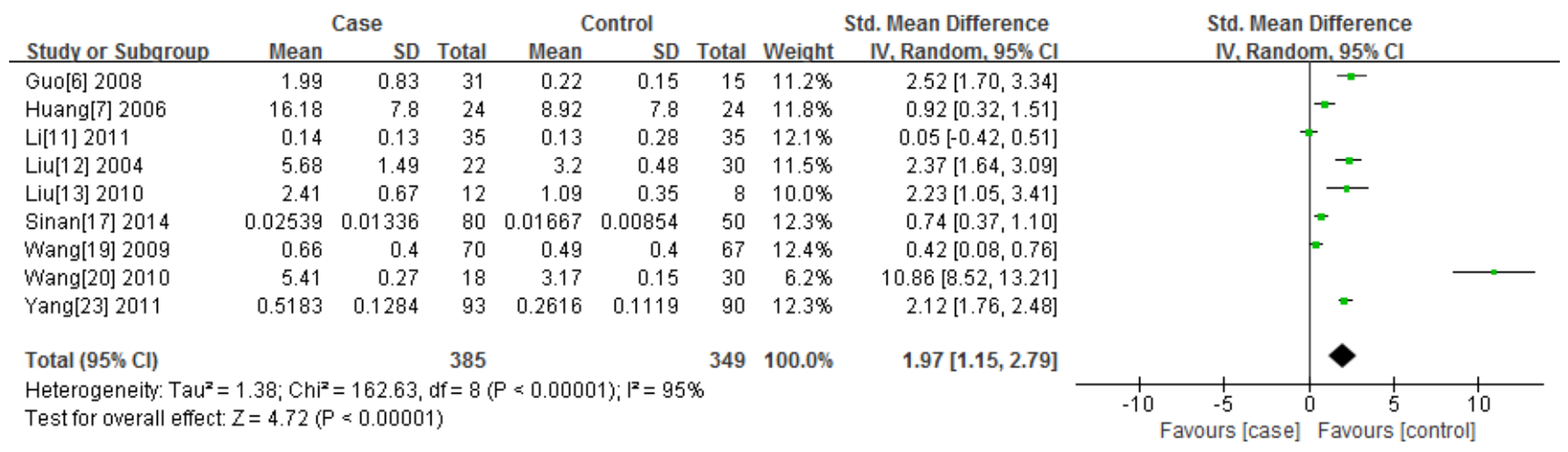

Figure 2: Forest plot of the serum resistin level between the study of SA and the normal control group, the horizontal lines correspond to the study-specific SMD and 95\% CI, respectively. The area of the squares reflects the study-specific weight. The diamond represents the pooled results of SMD and $95 \% \mathrm{CI}$. 


\section{Publication bias}

The publication bias was evaluated using the funnel plot. The funnel plot of each study is basically symmetrical. No visual publication bias was found, as shown in Figure 4.

\section{DISCUSSION}

The present meta-analysis was conducted by pooling both ORs and SMD and found that serum resistin levels may be an independent risk of CHD. It may be the first attempt to synthesize the existing studies to evaluate the association of serum resistin levels and CHD.

Resistin is secreted by white adipose tissue. It is a cysteine-rich protein which belongs to a family of cysteine-rich secretory proteins called resistinlike molecules (RELMs) [25]. Human resistin gene is located on chromosome 19, including four exons and three introns [26].
Elevated resistin levels were found in acute inflammation, accompany with several certain inflammatory factors [27] such as C-reactive protein, interleukin-6, and tumor necrosis factor. There are several studies about resistin levels and obesity-related cancer risk [28]. Many studies have shown that the resistance elements can be used as a marker of myocardial injury, diagnosis and prognosis of CHD.Verma et al [29] found that resistin activates human endothelial cells (ECs) in vitro; when incubated with ECs, recombinant resistin increases endothelin-1mRNA expression and protein secretion,also increases vascular cell adhesion molecule-1 and monocyte chemoattractant protein-1 expression, also impairs tumor necrosis factor receptor-associated factor-3 expression. These activities support the hypothesis that resistin and cardiovascular disease. A previous study reported by Lee et al [30] showed that resistin was an independent predictor of cardiovascular major adverse events in AMI patients. Yang et al. [23] found that plasma resistin may promote the formation of vulnerable plaque.

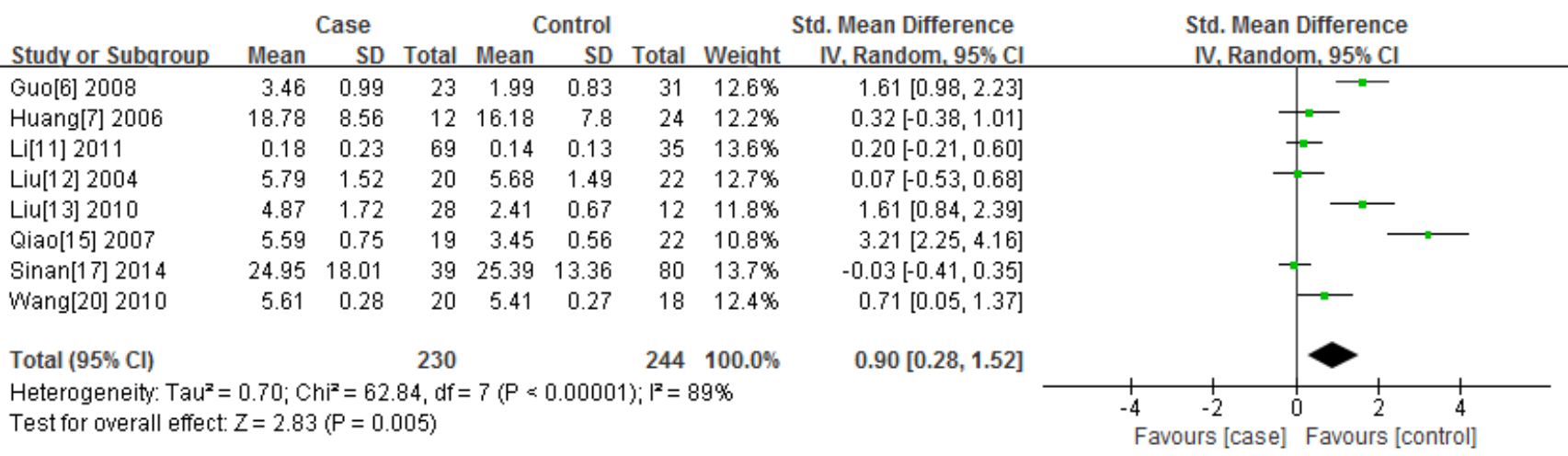

Figure 3: Forest plot of the serum resistin level between the study of the UA group and SA group, the horizontal lines correspond to the study-specific SMD and $\mathbf{9 5 \%}$ CI, respectively. The area of the squares reflects the study-specific weight. The diamond represents the pooled results of SMD and $95 \% \mathrm{CI}$.
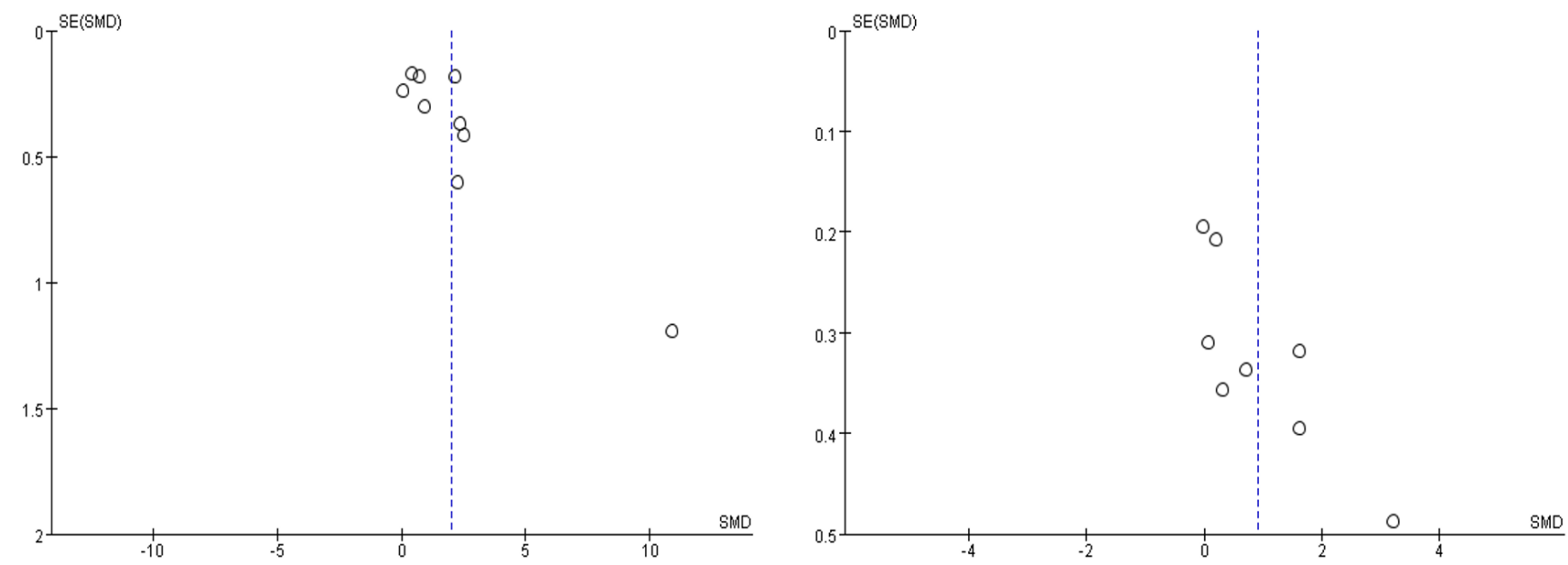

Figure 4: A. Funnel plot for publication bias tests about the serum resistin level between the study of SA and the normal control group. B. Funnel plot for publication bias tests about the serum resistin level between the study of the UA group and SA group. Each point represents a separate study for the indicated association. The horizontal and vertical axis correspond to the SMD and confidence limits. SMD standardized mean differences, SE standard error. 
Plasma resistin levels were significantly increased in CHD patients, especially in ACS, and gradually increased with the severity of CHD. Sinan 2014 [17] and Liu 2004 [12] found that increased serum resistin level is a predictor of CHD and there was a positive correlation between the Gensini score and the serum resistin level. The Gensini score is a parameter used to assess the prevalence and severity of CAD [31]. However, the relationship between increased serum resistin levels and pathogenic severity of CHD was not reported. In the present study, we conducted a meta-analysis of the published studies in order to evaluate the strength of the association between serum resistin level and different types of CHD.

The results showed that the standard deviation of resistin levels in SA, UA and AMI groups were higher compared to normal controls. Our Meta-analysis also found that the standard deviation of resistin levels in AMI patients is higher than UA and SA group, and UA group serum resistin levels is higher than the SA group. The result indicated that serum resistin levels gradually increased in SA group, UA group and AMI group, which suggested that serum resistin level and severity of CHD are closely related.

In addition, Erer HB [8] reported that serum resistin levels were similar in patients with STEMI and NSTEMI. Canga et al. [32] demonstrated a significant increase of serum resistin levels in patients with slow coronary flow compared to patients with normal coronary flow. Reilly et al reported that serum resistin level was independently associated with coronary artery calcification.

Heterogeneity is a potential problem that may affect the interpretation of the results. Heterogeneity may be attribute to the potential confounding resulted from diversity in sample-sizes, age, design, difference of testing instruments, severity of CHD, experimental method, and the interaction with other risk factor. To better interpret the results, other limitations of our meta-analysis should also be acknowledged. For one thing, the relative paucity of quality data and some inevitable publication bias may exist in our results. Only full text articles published in English and Chinese were included in this meta-analysis. Thus some eligible studies, which were unpublished or reported in other languages, were likely missed. Cultural background factors can also affect the decision to publish, making researchers more or less likely to report or edit negative results in some areas of research. For another, the characteristics of subjects, treatment plan and the difference of sampling time may have some effect on the results of the study. Furthermore, the difference between the reagents and the measuring instruments used in the research is the main reason of the heterogeneity of the study. We did not have access to enough data to make a subgroup analysis, this may affect the representative of our meta-analysis.

Despite these limitations or disadvantages, our metaanalysis did have some advantages. First, this is the first meta-analysis that consolidates the available information to explore the relationship between the serum resistin level and different types of CHD. A systematic review of the association between the serum resistin level and different types of CHD is able to overcome the limitation of the small sample sizes of the study populations by increasing the sample size, thus generating more robust data. Second, the quality of the case-control studies included in our meta-analysis was satisfactory and met our inclusion criteria.

In conclusion, serum resistin levels gradually increased with the severity of coronary heart disease, suggesting clinical serum resistin levels according to changes in the development of coronary heart disease can determine the extent of disease, disease forecasting, dynamic monitoring of serum resistin levels on the treatment and prognosis of coronary heart disease has clinical significance, reduce serum resistin levels of coronary heart disease is expected to become a new therapeutic target.

\section{MATERIALS AND METHODS}

\section{Literature search}

We searched literatures describing the association between resistin and different types of CHD, including acute myocardial infarction (AMI), stable angina (SA) and unstable angina (UA). Literature was retrieved by formal searching of electronic databases (PubMed, Web of Science, Google Scholar, the Cochrane Library, Wanfang Data, SinoMed and CNKI) and by hand searching of reference lists of related articles. These computer searches were limited to English and Chinese language articles before May 2015. The following keywords were used for searching: "acute myocardial infarction" OR "AMI" OR "stable angina" OR "SA" OR "unstable angina" OR "UA" OR "coronary heart disease" OR "CHD" OR "coronary artery disease" OR "CAD" OR "Acute coronary syndrome" OR "ACS" AND "serum resistin".

\section{Selection criteria}

The diagnosis and severity of CHD was fitted to the examination results of coronary arteriography, clinical symptoms combined with echocardiography, treadmill exercise test, electrocardiogram and myocardial perfusion imaging in Emission Computed Tomography.

The inclusion criteria were as follows: (1) Published literatures related to the association of serum resistin level with CHD, including stable angina (SA), unstable angina (UA) and acute myocardial infarction (AMI); (2) Independent case-control studies using either a hospitalbased or a population-based design; (3) The original 
studies must provide the number of each group and the mean and standard of serum resistin.

\section{Excluded criteria}

(1) Duplicated data; (2) the original data could not be extracted.

\section{Data extraction}

Two authors (JZ Zhang and Y Gao) independently extracted the original data. Disagreement was resolved by discussion. If the two authors could not reach a consensus, the result was reviewed by a third author (X Xie). The extracted data were consisted of the follow items: the first author's name, publication year, population(Ethnicity), methods, study design, matching criteria, sex, total number of cases and controls, and age (years).

\section{Quality assessment}

Study quality was assessed by the Newcastle-Ottaw scale [33], which uses a "star" rating system to judge the quality of all observational studies. The NOS ranges between zero (worst) up to nine stars (best). Studies with a score equal to or higher than seven were considered to be of high quality. Two investigators (Y Gao and YY Zheng) independently assessed the quality of the included studies, and the results were reviewed by a third investigator (YT $\mathrm{Ma}$ ). Disagreement was resolved by discussion.

\section{Statistical analysis}

We utilized Review Manager 5.33 (Cochrane Collaboration, The Nordic Cochrane Centre, Copenhagen) and Stata12.0 software to perform the meta-analysis in the present study. Heterogeneity among studies was assessed by $\mathrm{I}^{2}$ statistic, $P<0.10$ and $\mathrm{I}^{2}>50 \%$ indicated evidence of heterogeneity [34]. If heterogeneity existed among the studies, the random effects model [35] was used to estimate the pooled SMD. Otherwise, the fixed effects model [36] was adopted. The standard mean difference (SMD) and corresponding 95\% confidence interval (CI) was utilized to assess the associations. The potential publication bias was investigated using a funnel plot. Egger's test $(P<0.05)$ was also considered to be representative of statistically significant publication bias [37], which was conducted with the Stata12.0 software.

\section{ACKNOWLEDGMENTS}

This work was supported financially by the National Natural Science Fund of China (81560070).

\section{CONFLICTS OF INTEREST}

We state that we have no conflicts to disclose.

\section{REFERENCES}

1. Packard CJ, O'Reilly DS, Caslake MJ, McMahon AD, Ford I, Cooney J, Macphee CH, Suckling KE, Krishna M, Wilkinson FE, Rumley A, Lowe GD. Lipoproteinassociated phospholipase A2 as an independent predictor of coronary heart disease. West of Scotland Coronary Prevention Study Group. N Engl J Med. 2000; 343:11481155.

2. Sudhir K. Lipoprotein-associated phospholipase A2, vascular inflammation and cardiovascular risk prediction. Vasc Health Risk Manag. 2006; 2:153-156.

3. Cao HL, Shen XY, Wang GF, Zhu HZ. Study on the correlation between resistin and P-selectin levels in patients with acute coronary syndrome. Chin Cv Res J. 2009; 7:750753

4. Chu S, Ding W, Li K, Pang Y, Tang C. Plasma resistin associated with myocardium injury in patients with acute coronary syndrome. Circ J. 2008; 72:1249-53.

5. Geng HZ. To Explore the Level of Serum Resistin in Patients with Acute Coronary Syndrome and Its Clinical Significance. Med Info. 2013; 26:152-153.

6. Guo YM, Dang YH, Li YP. Detection of plasma resistin level in patients with coronary heart disease. Zhengzhou Univ J (Med Sci). 2008; 43:763-765.

7. Huang XS. Changes and clinical significance of acute coronary syndrome and serum resistin levels of endothelin-1. Central South Univ. 2006; 1: 1-121.

8. Erer HB, Sayar N, Guvenc TS, Aksaray S, Yilmaz H, Altay S, Turer A, Oz TK, Karadeniz FO, Oz D, Ekmekci A, Zencirci AE, Eren M. Prognostic value of serum resistin levels in patients with acute myocardial infarction. Kardiol Pol. 2014; 72:181-186.

9. Korah TE, Ibrahim HH, Badr EA, ElShafie MK. Serum resistin in acute myocardial infarction patients with and without diabetes mellitus. Postgrad Med J. 2011; 87:463467.

10. Li K, Ding WH, Shi LB. Study of serum resistin level in patients with acute coronary syndrome. Chin GHB \& VD J. 2006; 8:5-8.

11. Li L, Zhao HL, Zhang XD. Association between highsensitivity C-reactive protein and adiponectin, resistin in patients with non-ST elevated acute coronary syndrome. Practical Med J. 2011; 27: 3132-3134.

12. Liu LL. Resistin, HCY and coronary heart disease and other related research [D]. Shandong Univ. 2004; 1:1-128.

13. Liu CX. Correlation between serum Resistin levels, Cardiovascular Risk Factors, and the Severity of Coronary Stenosis in patients with Coronary Heart Disease. Shandong Univ. 2010; 1:1-110. 
14. Ma HH. C-reactive protein and resistin level difference between stable angina and acute myocardial infarction. Comm Med J. 2008; 22:500-502.

15. Qiao XZ, Yang YM, Xu ZR, Yang LA. Relationship between resistin level in serum and acute coronary syndrome or stable angina pectoris. J Zhejiang Univ Sci B. 2007; 8:875-80.

16. Sang L. The changes of serum level of adiponetin, resistin and CRP in old patients with CHD. Chin \& For Med Res. 2009; 7:4-7.

17. Sinan UY, Canbolat IP, Baydar O, Oktay V, Imre G, Kocas C, Abaci O, Coskun U, Bostan C, Kilickesmez KO, Yildiz A, Kaya A, Gurmen T, et al. Relationship between increased serum resistin level and severity of coronary artery disease. Angiology. 2014; 65:239-42.

18. Tang B. Change of Plasma Resistin Concentration in Patients with Acute Myocardial Infarction ST-segment Elevation. Chin Mod Doc. 2011; 49:16-17.32.

19. Wang H, Chen DY, Cao J, He ZY, Zhu BP, Long M. High serum resistin level may be an indicator of the severity of coronary disease in acute coronary syndrome. Chin Med Sci J. 2009; 24:161-6.

20. Wang $X$. The serum resistin and adiponectin levels in patients with coronary disease. Neimongol Med Un i v J. 2010; 32:480-482.

21. Wang L. The analysis of serum adiponectin and resistin change in patients with Coronary heart disease. Practical Med J. 2012; 7:108-110.

22. Wang CF. THE association of acute coronary syndrome risk factors and their correlations with plasma resistin. Dalian Med Univ. 2012; 1:1-131.

23. Yang LX, Li JS, Qi F. The clinical significance of plasma resistin levels in patients with acute coronary syndrome. Chin Physician J. 2011; 13:611-614.

24. Zhang RX, Zhu J, Wang SW. Study of Serum Resistin and Adiponectin Levels in Patients with Acute Coronary Syndrome. Clin Res J. 2009; 26:464-466.

25. Steppan CM, Bailey ST, Bhat S, Brown EJ, Banerjee RR, Wright CM, Patel HR, Ahima RS, Lazar MA. The hormone resistin links obesity to diabetes. Nature. 2001; 409:307312.

26. Banerjee RR, Lazar MA. Dimerization of resistin and resistin-like molecules is determined by a single cysteine. $\mathrm{J}$ Biol Chem. 2001; 276:25970-25973.
27. Reilly MP, Lehrke M, Wolfe ML, Rohatgi A, Lazar MA, Rader DJ. Resistin is an inflammatory marker of atherosclerosis in humans. Circulation. 2005; 111: 932-939.

28. Gong WJ, Zheng W, Xiao L, Tan LM, Song J, Li XP, Xiao D, Cui JJ, Li X, Zhou HH, Yin JY, Liu ZQ. Circulating resistin levels and obesity-related cancer risk: A metaanalysis. Oncotarget. 2016; 7: 57694-57704. doi: 10.18632/ oncotarget.11034.

29. Verma S, Li SH, Wang CH, Fedak PW, Li RK, Weisel RD, Mickle DA. Resistin promotes endothelial cell activation. Further evidence of adipokine-endothelial interaction. Circulation. 2003; 108:736-40.

30. Lee SH, Ha JW, Kim JS, Choi EY, Park S, Kang SM, Choi D, Jang Y, Chung N. Plasma adiponectin and resistin levels as predictors of mortality in patients with acute myocardial infarction:data from infarction prognosis study registry. CAD. 2009; 20: 33-39.

31. Tsuiki K, Oguma M, Kubota I, Ohta I, Tono-Oka I, Yasui S. Predictability of stress-induced myocardial ischemia from coronary arteriography in patients with organic coronary artery stenosis. J Cardiogr Suppl. 1987; 12:19-26.

32. Canga A, Cetin M, Kocaman SA, Durakoğlugil ME, Kırbaş A, Erdoğan T, Temiz A, Yılmaz A, Ciçek Y. Increased serum resistin levels in patients with coronary slow-flow phenomenon. Herz. 2013; 38:773-8.

33. Cota GF, de Sousa MR, Fereguetti TO, Rabello A. Efficacy of anti-leishmania therapy in visceral leishmaniasis among HIV infected patients: a systematic review with indirect comparison. PLoS Neg1 Trop Dis. 2013; 7:e2195.

34. Ioannidis JP, Patsopoulos NA, Evangelou E. Heterogeneity in meta-analyses of genome-wide association investigations. PLoS One. 2007; 2:e841.

35. DerSimonian R, Kacker R. Random-effects model for metaanalysis of clinical trials: an update. Contemp Clin Trials. 2007; 28:105-114.

36. Mantel N, Haenszel W. Statistical aspects of the analysis of data from retrospective studies of disease. J Natl Cancer Inst. 1959; 22:719-748.

37. Egger M, Davey Smith G, Schneider M, Minder C. Bias in meta-analysis detected by a simple, graphical test. BMJ.1997; 315:629-634. 